\title{
Psicologia Escolar no Maranhão: História da Formação e Tendências Atuais para Atuação
}

\author{
School Psychology in Maranhão: History of Training and Current Performance Trends
}

\section{Psicología Escolar en Maranhão: Historia de la Formación y Tendencias Actuales de Actuación}

\author{
Pollianna Galvão \\ Doutora em Psicologia, Professora e pesquisadora do Curso de Psicologia da Universidade CEUMA \\ E-mail: polliannagalvao@yahoo.com.br \\ Tatiana Oliveira de Carvalho \\ Mestre em Psicologia, Professora do Instituto Geist \\ E-mail: tatiana@geist.com.br \\ Daniel Carvalho de Matos \\ Doutor em Psicologia, Professor e pesquisador do Curso de Psicologia da Universidade CEUMA \\ E-mail: dcmatos23@hotmail.com
}

\begin{abstract}
Resumo
Esse artigo discute aspectos históricos sobre a formação em Psicologia Escolar no Maranhão, a partir de fontes documentais e literatura da área produzida no estado. Na intenção de realizar uma análise crítica e contextualizada sobre o percurso da inserção da área no cenário maranhense, será necessário considerar fatores relacionados à trajetória nacional da Psicologia e os desdobramentos à formação e atuação no cenário regional. Na primeira parte, serão apresentadas informações históricas da formação em Psicologia no Maranhão, no contexto da Psicologia no Brasil. Seguidamente, será discutido o panorama da formação de psicólogos escolares maranhenses, destacando-se as transformações ocorridas nas últimas décadas no contexto das Instituições de Ensino Superior, com destaque à Universidade Federal do Maranhão e Universidade CEUMA. Por fim, serão tecidas reflexões sobre as tendências e desafios da formação concernentes às demandas regionais de atuação do psicólogo escolar, a partir de dados do Conselho Regional de Psicologia do Maranhão.
\end{abstract}

Palavras-chave: psicologia escolar, história, formação, atuação.

\section{Abstract}

This article discusses historical aspects about the education in School Psychology in Maranhão, from documentary sources and locally produced literature of the area. In order to carry out a critical and contextualized analysis upon the insertion of such matter in Maranhão's scenario, it will be necessary to consider factors related to the national trajectory of Psychology and its ramifications for education and performance in the regional scenario. In the first part, it will be presented historical information on the training in Psychology in Maranhão, within the context of Psychology in Brazil. Secondly, the panorama of education of school psychologists in Maranhão will be discussed: transformations occurred through the last decades in the context of Higher Education Institutions will be highlighted, with focus on the Federal University of Maranhão and CEUMA University. Finally, it will construct some reflections over training trends and challenges, regarding the regional demands of school psychologists, based on data from the Regional Council of Psychology in Maranhão.

Keywords: school psychology, history, formation, performance. 


\section{Resumen}

Este artículo discute aspectos históricos sobre la formación en Psicología Escolar en Maranhão, a partir de fuentes documentales y literatura del área producida en dicho estado. Para realizar un análisis crítico y contextualizado sobre el recorrido de la inserción del área en el escenario de Maranhão, será necesario considerar factores relacionados con la trayectoria nacional de la Psicología y los desarrollos en la formación y actuación en el escenario regional. En la primera parte, se presentarán informaciones históricas de la formación en Psicología en Maranhão, en el contexto de la Psicología en Brasil. En seguida, se discutirá el panorama de la formación de psicólogos escolares de Maranhão, destacando las transformaciones ocurridas en las últimas décadas en el contexto de las Instituciones de Enseñanza Superior, con especial énfasis en la Universidad Federal de Maranhão y la Universidad CEUMA. Por último, se tejen reflexiones sobre las tendencias y desafíos de la formación con respecto a las demandas regionales de actuación del psicólogo escolar, a partir de datos del Consejo Regional de Psicología de Maranhão.

Palabras-clave: psicología escolar, historia, formación, actuación.

\section{Contextualizando a Psicologia Escolar no Maranhão a partir da História}

Para se compreender a Psicologia no Maranhão no âmbito de avanços, mudanças e problemas atuais, é de fundamental importância destacar os principais aspectos de sua história no contexto local. As informações a serem apresentadas sobre a história da Psicologia Escolar no Maranhão estão baseadas em referenciais teóricos regionais de pesquisadores e estudiosos que se dedicaram à recuperação e à sistematização desta temática (Aires, Soares, \& Carvalho, 2011; Araújo, 2005a, 2005b; Carvalho, 2007; Carvalho \& MarinhoAraujo, 2009; Ribeiro, 2015; Ribeiro \& Galvão, no prelo; Soares, 2008). Os dados históricos e contemporâneos apresentados também estão fundamentados em informações públicas de sites das instituições de ensino superior do Maranhão que possuem a formação em Psicologia; e de documentos públicos da Comissão de Psicologia Escolar e Educacional do Maranhão do Conselho Regional de Psicologia 22 ${ }^{\mathrm{a}}$ Região (Conselho Regional de Psicologia do Maranhão, 2008, 2015a, 2015b; 2016), visando contribuir e incentivar o aumento da historiografia da área na região maranhense.

A história da Psicologia no Brasil, já bastante difundida por estudiosos que se dedicaram à tarefa de delinear o seu percurso de consolidação como ciência e profissão, confirma uma trajetória complexa no âmbito das filiações filosóficas, epistemológicas e políticas, que fundamentaram diferentes paradigmas teórico-práticos rumo à Psicologia Escolar crítica (Antunes, 2003, 2008, 2011; Barbosa, 2012; Barbosa \& Souza, 2012; Bock, 1999; Correia \& Campos, 2004; Guzzo, 2005, 2008, 2011; Guzzo, Costa, \& Sant'Anna, 2009; Guzzo, Mezzalira, Tizzei, \& Netto, 2010; Maluf \& Cruces, 2008, Marinho-Araujo, 2007, 2009, 2010, 2014, 2016; Marinho-Araujo \& Almeida, 2005; Massimi, 1990; Massimi \& Guedes, 2004; Meira, 2000, 2012; Neto, Guzzo, \& Moreira, 2014, Oliveira \& Marinho-Araujo, 2009; Patto, 1999, 2005, 2008; Tanamachi, 2000; Tanamachi \& Meira, 2003). O propósito de trazer os principais marcos desse percurso se dá pelo entendimento de que a Psicologia Escolar no Maranhão é uma produção social construída nessa realidade com suas nuances e características próprias, mas intimamente articulada ao movimento histórico da consolidação da ciência e profissão da Psicologia no país.

Na literatura da ciência psicológica, registra-se que a Psicologia se difundiu no Brasil na transição do século XIX para o século XX, no campo do saber e das ideias que subsidiaram pesquisas nas áreas da Medicina e da Pedagogia, auxiliando compreensões diferentes (e até divergentes) em relação aos objetos de estudo dessas disciplinas (Tanamachi, 2000). Com a crescente demanda por profissionalização, surgiam na década de 1930 os primeiros credenciamentos de cursos 
para a preparação da formação em Psicologia, despontando um período de sua consolidação como área de conhecimento e prática.

Destaca-se que uma das principais bases para a consolidação da Psicologia no país foi o ensino de Psicologia nas escolas normais na formação de professores. De acordo com Antunes (2008, 2011) e Meira (2000), essa via possibilitou a origem das cátedras de Psicologia Educacional nos primeiros cursos de Pedagogia, e anos depois fortaleceram a constituição dos primeiros cursos de Psicologia. É conclusivo assumir que a Psicologia foi materializada como ciência e profissão no país pelas influências advindas da área da Educação, o que legitima o reconhecimento da Psicologia Escolar e Educacional, no campo da pesquisa e atuação, como uma das áreas pioneiras em seu princípio. "Ensino, pesquisa, publicações, criação de associações e realização de congressos articulavam-se ao estabelecimento do campo de ação da Psicologia que, da Educação, ampliavase para a organização do trabalho e da clínica" (Antunes, 2011, p. 22).

Na década de 1950, já existia a graduação em Psicologia no país, e na década seguinte, por meio da Lei $n^{\circ} 4.119$ (de 27 de agosto de 1962), foram regulamentados a profissão de psicólogo e o currículo mínimo para a sua formação (Guzzo, 2011). Até o ano de 1967, somavam-se, em todo o país, 30 cursos nessa área (Neto et al., 2014). Antunes (2011) destaca que se tratava de um período em que a reforma universitária, subsidiada por uma política de internacionalização da economia pós-golpe militar de 1964, incentivou a ampliação do ensino superior pela privatização, aumentando a quantidade de psicólogos com formação ainda precária e com poucas possibilidades de inserção profissional. Neto et al. (2014) destacam que, nesse período, os serviços de Psicologia foram construídos para atender a demandas da escola sob a lógica da saúde mental no contexto escolar, o que pulverizou muitos serviços, em especial na região sudeste, que priorizavam atendimentos especializados com base em uma perspectiva médica e terapêutica. Pesquisas de Patto $(1999,2005,2008)$ e Collares e Moysés $(1992,1996)$ também confirmam a ênfase dos modelos clínicos de atuação para as questões escolares.

Como destaca Yazlle (citado por Neto et al., 2014), o crescimento da Psicologia no país, ante a regulamentação da profissão em suas décadas iniciais, despontava avanços técnicos alicerçados em conservadorismo e reprodutivismo social, o que deu origem a "práticas individualizantes e ajustatórias, com ênfase nos processos de aprendizagem e nos processos remediativos como solução dos chamados problemas escolares" (p. 4). A formação da Psicologia no país sofreu influências das práticas e da organização da sociedade em cada período de sua história, implicando em desdobramentos quanto à ampliação das instituições formadoras ao longo dos anos.

\section{A Psicologia no Maranhão}

O percurso histórico da consolidação da Psicologia no país, no âmbito da formação e atuação, concentra especificidades que, somadas ao panorama sociopolítico e econômico de algumas regiões menos desenvolvidas, como o Maranhão, justificam a chegada dos cursos décadas depois à sua regulamentação. Especificamente, a chegada da Psicologia ao Maranhão ocorreu nos anos 1990 pelas mesmas vias que marcaram sua chegada a outras regiões do Brasil, e bem tardiamente em comparação ao período de sua regulamentação. Contudo, ela trilhou trajetórias semelhantes daquelas que figuraram o panorama da área no país, especialmente no âmbito da filiação teóricometodológica que orientou as primeiras práticas desse profissional (Araújo, 2005a, 2005b).

No cenário regional maranhense, a Psicologia entrou como campo de saber atrelado à prática profissional de pediatras, e mais fortemente de psiquiatras devido a um contexto favorável à 
fundação dos hospitais de saúde mental entre os anos 1940 e 1950 na capital do estado. O acompanhamento psicoterápico era realizado por médicos e detinha caráter de assistência a enfermos mentais que eram abrigados pelos institutos de psiquiatria. Segundo Araújo (2005b),

no Maranhão, esse saber esteve por muitos anos ocasionalmente atrelado à figura de médicos-pediatras, assim como em especial à dos psiquiatras, pois em suas instituições estava centralizado o tratamento relativo à saúde mental. Quanto à participação dos médicospediatras nessa área, dados colhidos mostram a frequência com que esses profissionais eram procurados para atendimentos de cunho psicológico (p. 146).

Ainda que os primeiros hospitais de saúde mental tenham se instaurado entre as décadas de 1940 e 1950, apenas em 1987, mais de 30 anos depois, registraram-se os primeiros psicólogos atuantes nessas instituições, mesmo sem qualquer vínculo formal de trabalho (Araújo, 2005a, 2005b; Carvalho, 2007; Carvalho \& Marinho-Araujo, 2009; Soares, 2008). Era um momento em que havia pouco conhecimento sobre as especificidades profissionais do psicólogo para o mercado de trabalho.

AEducação foi outra via de chegada da Psicologia no Maranhão. Coerente com o panorama nacional, a área se inseriu na região por intermédio das escolas normais que surgiam na segunda metade do século XIX, para habilitação na carreira do magistério (Carvalho \& Marinho-Araujo, 2009). Com o objetivo de capacitar os profissionais da Educação, a Psicologia passou a ser disciplina ofertada nesses cursos devido ao período de ampliação do sistema de ensino do país (Neves, 2007; Marinho-Araujo, 2010; Massimi, 1990).

No contexto local, o Liceu maranhense ganhou destaque nos anos 1960 pelo número de professores formados para o magistério, ainda que o escopo dessa formação se limitasse à capacitação dos filhos da elite e estivesse a serviço da manutenção das relações de poder (Ribeiro,
2006). Compreendida por Ribeiro (2006) como uma ciência jovem no contexto maranhense nos anos 1960, a Psicologia foi tomada como um dos fundamentos da formação pedagógica desenvolvida pela escola secundária do estado. Contudo, afirma Araujo (2005a, 2005b), essa disciplina era ministrada por profissionais da Enfermagem, dada a ausência de docentes com formação na área psicológica. De acordo com a autora, a disciplina que permanecia no currículo das Escolas Normais era intitulada de Psicologia Aplicada e Ética Profissional. Percebia-se a falta de especificidade da Psicologia como campo de saber voltado para a formação profissional de outras áreas.

Embora já existissem campos propícios para a atuação dos psicólogos, como as instituições de ensino, organizações, empresas e hospitais, foi em meados dos anos 1970 que a população maranhense começa a ter conhecimento sobre os serviços oferecidos pela Psicologia (Araujo, 2005a, 2005b). O registro dos primeiros psicólogos no Maranhão data entre as décadas de 1970 e 1980, migrados de outros estados, como Brasília, Pernambuco e Paraíba (Aires et al., 2011; Araujo, 2005a, 2005b; Carvalho, 2007). De acordo com Araujo (2005a), a escolha pela migração para a região maranhense se deveu especialmente pela abertura dos primeiros empregos públicos e privados na área, associado ao fato de que esses psicólogos tinham parentes e amigos na região.

Em um contexto de governança militar e de psicologização das questões sociais mais amplas e complexas (Antunes, 2008, 2011), a Psicologia da década de 1970 nessa região foi pouco expressiva e limitou-se à prestação de serviços a empresas (como atividades de exames psicotécnicos em empresas filiadas ao Departamento Estadual de Trânsito - DETRAN) e em consultórios clínicos. De acordo com Araújo (2005a), Carvalho e MarinhoAraujo (2009), Galvão (2016) e Soares (2008), a atuação de psicólogos nesse período também ocorria no campo educacional, embora de modo restrito, limitado à aplicação de testes psicológicos, como os de avaliação vocacional. Ainda que o cenário nacional despontasse para a ampliação 
de serviços de Psicologia nas escolas públicas, devido à ampliação do sistema educacional (Neves, 2007), no Maranhão isso não foi evidenciado. $O$ que se observou era que os psicólogos ofereciam serviços a uma parte minoritária da população, notadamente à classe da elite social. Araujo (2005a) afirma que

Os trabalhos que foram desenvolvidos na área da Psicologia em São Luís nesse período foram poucos em decorrência de alguns fatores: $o$ mercado de trabalho não estava aberto nem sensibilizado para essa profissão, havia poucos profissionais, além da falta de conhecimento da atuação do psicólogo, o que dificultava suas atividades até mesmo nas instituições em que iniciaram seus trabalhos (p. 153).

Na década de 1980, enquanto a Psicologia brasileira vivia um momento de intensas e significativas ressignificações, organização profissional em sindicatos e associações, envolvimento de psicólogos nos movimentos préconstituintes (Marinho-Araujo, 2010), nem sequer havia essa formação no Maranhão, e sim um desconhecimento generalizado acerca da atuação desse profissional no cenário regional. Mesmo com a chegada de psicólogos no estado, era comum que as pessoas procurassem, em detrimento desses, $\mathrm{o}$ Pe. João Mohana (1925-1995), para tratarem de assuntos de ordem psicológica, sem diferenciarem atendimento psicológico do religioso. Araújo (2005b) e Galvão (2016) relatam que esse padre, estudioso da ciência psicológica, recebia grande reconhecimento por parte da população, por seu trabalho pautado em uma "Psicologia iluminada pela fé" (p. 148).

Galvão et al. (2016), em uma pesquisa realizada sobre a história da Psicologia em ONGs educativas no Maranhão, afirmam que os seminaristas, na década de 1980, recebiam a formação de Pe. João Mohana para atendimentos individuais no contexto da Igreja com base nessa perspectiva, sendo uma prática disseminada entre os líderes religiosos desta época. Muitos desses líderes, fundamentados pelos pressupostos da doutrina de João Mohana, incitavam e apoiavam a protagonização de espaços de educação não formal para o ensino da catequese e para a assistência educacional de crianças que não estavam no sistema regular de ensino. Nas décadas de 1980 e 1990, o formador atuava no Instituto de Ensino Superior do Maranhão (IESMA) na formação filosófica e teológica dos futuros presbíteros da Igreja Católica do Maranhão, bem como realizava acompanhamento psicológico e espiritual dos seminaristas e da população maranhense. Atuava junto a grupos de jovens para orientação profissional, da carreira e formação de opinião para o trabalho em sociedade (inclusive escreveu a obra Autoanálise para o Êxito Profissional, em 1957). Essas primeiras articulações entre Psicologia e Religião derivadas dos estudos e ensinamentos de Pe. João Mohana fundamentaram a disseminação das primeiras práticas de atendimento psicológico individual no contexto maranhense, ainda que atreladas aos aspectos da religiosidade (Galvão, 2016). Uma universidade privada no Maranhão, a ser alvo de nossa análise ainda neste artigo, intitulou a clínica-escola do Curso de Psicologia com o nome Clínica de Psicologia Pe. João Mohana, em homenagem ao referido padre.

No cenário nacional, Antunes (2011) destaca que, entre as décadas de 1970 e 1980, assistia-se a uma transição de interesse de atuação da prática psicológica. Os psicólogos passaram a migrar para as outras áreas da Psicologia devido ao aumento das críticas endereçadas aos primeiros modelos de atuação do psicólogo no campo da educação e às primeiras relações estabelecidas entre Psicologia e Educação. "Se antes a educação constituía-se o principal campo de atuação para a Psicologia, nesse momento a clínica passou a ser a modalidade preferida de atuação para graduandos e jovens psicólogos, seguida do campo da organização do trabalho" (Antunes, 2011, p. 25).

$\mathrm{Na}$ esteira dessa transição, a ampliação do trabalho do psicólogo maranhense foi lentamente se estabelecendo nas décadas de 1980 e 1990, especialmente com a difusão da prática clínica em Psicologia no país. Registraram-se, nesse período, a fundação das primeiras escolas de 
Psicanálise e formação de núcleos de estudos compostos por psicólogos e psiquiatras em São Luís para a ampliação da prática clínica na região (Araújo, 2005a). Pode-se destacar, por exemplo, a Delegação Geral Maranhão-EBP da Escola Brasileira de Psicanálise instituída nesse período. Outra via de inserção dos psicólogos no mercado de trabalho se deu por meio dos concursos públicos da Secretaria de Educação Municipal, ocorridos no final da década de 1980, os quais passaram ocupar atividades relacionadas à educação especial (Conselho Regional de Psicologia, 2015b).

O fortalecimento de grupos profissionais nesses espaços, associado ao contínuo aumento da demanda por serviços em Psicologia pelo mercado de trabalho, favoreceu a criação dos dois primeiros cursos de graduação na área, em São Luís, na década de 1990. Em 1991, a Universidade Federal do Maranhão (UFMA) ofereceu bacharelado em Psicologia e formação de psicólogo, legitimado pela Resolução n ${ }^{\circ}$ 13/90 do CONSUN (Conselho Universitário). Ao final da década, em 1998, o Centro Universitário do Maranhão (UNICEUMA), primeira instituição de ensino superior da rede privada do estado, ofereceu formação em Psicologia na capital. Nesta última instituição, a ênfase no modelo clínico para a formação em Psicologia deu forma às primeiras práticas e dinâmica do ensino, sobretudo com a orientação normativa de uso de roupas brancas para os estudantes do curso, prática já extinta na referida instituição, e o uso de jaleco branco na clínica-escola de diferentes áreas da saúde para o estágio em Psicologia Clínica, prática mantida até a atualidade por atendimento às normas institucionais da Clínica Integrada (Universidade Ceuma, 2014).

Ao longo dos anos 2000, os cursos de Psicologia oferecidos no Maranhão continuaram crescendo especialmente na capital, a reboque da expansão do ensino superior que se assistia na virada do milênio (Dias Sobrinho, 2013; Marinho-Araujo, 2007, 2009; Polidori, 2009). Em 2008, outra instituição de ensino superior da rede privada, a Faculdade Pitágoras, abriu o terceiro curso de Psicologia no estado. Oito anos depois, duas novas IES abriram novos cursos na área regulamentados junto ao MEC: em 2014 pela Faculdade Maurício de Nassau, e em 2016 a Unidade de Ensino Superior Dom Bosco (UNDB).

Nesse mesmo ano, o cenário dos cursos de formação em Psicologia reconhecidos pelo MEC ampliou-se para os municípios de maior destaque socioeconômico. A Unisulma, ainda no primeiro semestre de 2016, abriu a primeira turma em Psicologia em Imperatriz, município situado na região sudoeste do estado, e a segunda mais populosa, concentrando 253.873 habitantes e ocupando o segundo lugar em relação ao maior índice de PIB do estado. Ainda em 2016, a Faculdade de Ciências e Tecnologia (FACEMA) passou a ofertar a formação de psicólogo em Caxias - quinta maior cidade do estado, com uma população de 161.137 habitantes, é considerada um dos maiores polos econômicos em função da concentração de setores industriais e da sua proximidade com a fronteira do estado do Tocantins. No primeiro semestre de 2017, a Universidade Ceuma lançou oferta do curso de Psicologia no campus do município de Imperatriz. Importante mencionar que existe, atualmente, uma iniciativa de implementação de um curso situado em uma IES no município de Pedreiras.

Com esses dados, constata-se a existência de oito cursos existentes no Maranhão até a data atual - cinco concentrados na capital ludovicence, e três distribuídos entre dois municípios do continente. Concorda-se com a ressalva de Guzzo (2011): o rápido crescimento do número de IES que oferecem curso de Psicologia não tem acompanhado o aumento da inserção profissional nos diferentes campos de trabalho, o que leva à preocupação sobre a qualidade da formação, inicial e continuada, oferecida para atender aos diversos campos de atuação da profissão. É importante avaliar as demandas de trabalho e o perfil dos profissionais que vem sendo desenvolvido na esteira da expansão do ensino superior, despontando para renovados e ressignificados desafios da atualidade (Marinho-Araujo, 2007, 2009, 2014).

Atualmente, de acordo com o cadastro do e-Mec, existem cerca de 770 cursos de 
Psicologia em toda a região nacional, o que reflete sobre o crescimento da área no país, e como desdobramento um crescimento de profissionais cadastrados do Sistema Conselhos, que já somam 294.641 registros, dos quais 2.184 pertencem ao Maranhão. Para o cenário brasileiro em geral e a região maranhense em específico, é necessário refletir criticamente sobre a consolidação de políticas do ensino superior que visam à ampliação deste sistema de ensino (Marinho-Araujo, 2009) e de políticas de avaliação para o monitoramento da qualidade da educação oferecida (Rabelo, 2013). Esse cenário provoca desdobramentos às instituições em suas políticas e diretrizes de ensino e avaliação. É importante assegurar a qualidade da educação oferecida para a permanência, humanização e democratização de oportunidades ao estudante em sua trajetória acadêmica, a fim de impactar na transformação social esperada a cada realidade regional (Dias Sobrinho, 2013; Marinho-Araujo, 2009; Polidori, 2009; Rabelo, 2013).

\section{A formação em Psicologia Escolar no Maranhão: um olhar retrospectivo da área e as características atuais}

O Maranhão apresenta um panorama desafiador à formação dos psicólogos e um alerta sobre os possíveis impactos à atuação profissional. Atualmente, o Conselho Regional de Psicologia da $22^{a}$ Região registra um quantitativo de cerca de 2.200 psicólogos cadastrados na referida autarquia, números que tendem a um rápido crescimento em função do quadro da formação inicial apresentado. É importante destacar que, apesar de se assistir ao aumento da formação de psicólogos, nem todas as IES concentram profissionais especializados nas áreas da Psicologia, como a Psicologia Escolar e Educacional (Aires et al., 2011; Carvalho, 2007; Soares, 2008).

Abordar a formação especificamente em Psicologia Escolar no estado do Maranhão implica contextualizá-la na história das primeiras articulações entre Psicologia e Educação em seu âmbito social e cultural no Brasil, especialmente a partir do movimento de revisão crítica da área iniciado nos anos 1980, década precedente à chegada do primeiro curso de Psicologia no Maranhão. Essas informações cumprem importante papel na medida em que demonstram os indicadores históricos que modificam a profissão em seus avanços e retrocessos (Guzzo, 2011). Nessa seção, nos deteremos a trazer as informações sobre a Universidade Federal do Maranhão e a Universidade Ceuma.
Estudiosos da história da Psicologia Escolar e Educacional no país, como Antunes (2003, 2008, 2011); Barbosa (2012); Meira, (2000, 2012) e Tanamachi (2000), destacam que os paradigmas tradicionais que orientaram as primeiras práticas psicológicas estavam associados às tendências psicométrica, experimental e tecnicista balizadas fundamentalmente pelos padrões de ciência moderna vigentes nas décadas de 1960 e 1970. Essas tendências alimentaram uma postura do psicólogo escolar normatizadora, com base em padrões de desenvolvimento e aprendizagem aos quais os alunos deveriam se enquadrar. Isso deu forma a uma atuação médica ou psicoterapêutica no interior da escola, fortalecida por teorias psicológicas naturalizantes do desenvolvimento humano.

O problema gerado ao se privilegiar esse modelo de trabalho foi criar uma cultura psicologizante e individualizante dos problemas da escola. Havia uma forte tendência em se proporem soluções para as queixas escolares pautadas em intervenções desalinhadas às questões institucionais, sociais, políticas e econômicas (Antunes, 2003, 2008, 2011; Cunha \& Dazzani, 2016; Guzzo, 2008; Guzzo, Mezzalira, Moreira, Tizzei, \& Neto,2010; Guzzo et al., 2009; Marinho-Araujo, 2010, 2014; Neves, 2007; Patto, 1999, 2008).

Em seu princípio, a Psicologia desencadeou uma visão reducionista do processo escolar e 
contribuiu para ocultar as origens políticas e econômicas dos problemas sociais em um período que a educação pública passou a ser vista como meio democrático legítimo para a equalização das desigualdades sociais (Marinho-Araujo, 2010, 2014, 2016). Durante as décadas de 1960 e 1970, a área corroborou o conservadorismo e o reprodutivismo social na medida em que difundia um modelo de atuação que propunha o tratamento dos problemas escolares com ênfase remediativa e adaptativa. Em decorrência de uma visão acrítica e a-histórica acerca da complexidade inerente à realidade educativa, as ações dos psicólogos escolares eram pouco eficazes, educação pública e não colaboravam para a transformação do cotidiano das escolas (Guzzo, 2008).

A década de 1980 demarcou um importante momento na história da Psicologia no Brasil. Esse período foi caracterizado pelo rompimento da tradição individualista, naturalizante, psicologizante das questões sociais que dominavam a Psicologia desde sua regulamentação como profissão. No entanto, essa ruptura desencadeada ao longo das décadas de 1980 e 1990 não foi suficiente para vencer a visão liberal, positivista e idealista de um homem isolado da sociedade, tendências essas que influenciaram, sobremaneira, a formação em Psicologia nos cursos de graduação na década de 1990 (Bock 1999; Marinho-Araujo \& Almeida, 2005; Meira, 2000, 2012).

A Psicologia Escolar brasileira também começou a buscar recursos para atender a esse novo momento histórico da Psicologia, e passou a desenvolver uma crítica interna à sua prática. As transições de paradigmas, as mudanças teóricometodológicas ancoradas na necessidade de uma Psicologia comprometida com as mudanças sociais, entre outros aspectos, nos remete à reflexão sobre a formação do profissional de Psicologia como perspectiva de alcançar essa nova demanda (Guzzo, 2011).

A revisão crítica da área passava pela necessidade em se compreender a origem do pensamento psicológico, as práticas prioritárias dos psicólogos escolares e as demandas educacionais em sua relação com as formas de organização socioeconômica (Guzzo, 2008; Marinho-Araujo, 2010, 2014). Instaurou-se um período em que se buscavam alternativas de formação mais eficazes e coerentes com a realidade escolar brasileira, caminhando ao encontro dos processos sociopolíticos vinculados à democratização do Estado, que se estenderam à década de 1990 (Antunes, 2004, 2008, 2011; Guzzo, 2005, 2008; Marinho-Araujo, 2010; Marinho-Araujo \& Almeida, 2005a; Massimi \& Guedes, 2004; Neves, 2007; Oliveira \& MarinhoAraujo, 2009; Patto, 1999, 2005, 2008).

Em meio a um cenário de mudanças nos paradigmas iniciais da Psicologia, a década de 1990 representa um momento de avanços nas ações da Psicologia na Educação, rompendo com a tradição de uma atuação individualista, naturalizante e patologizante da ciência e prática psicológica, e aspirando rumos politicamente comprometidos com a transformação social. Buscando responder ao apelo de busca de mudanças das condições de vida dos sujeitos atores do cenário da escola, a Psicologia Escolar brasileira inicia essa década com diversos movimentos e ações acadêmicas que vieram a fortalecer a nova proposição de paradigma que imputava uma nova acepção da identidade do psicólogo escolar. Instituiu-se, por exemplo, o Grupo de Trabalho de Psicologia Escolar/Educacional da Associação Nacional de Pesquisa e Pós-Graduação em Psicologia - ANPEPP, por professores de graduação e pós-graduação na área, e a Associação Brasileira de Psicologia Escolar e Educacional - ABRAPEE, por psicólogos interessados em congregar os estudiosos e profissionais que objetivavam incentivar a melhoria da qualificação e serviços profissionais, além de estimular e divulgar pesquisas em Psicologia Escolar. É nesse cenário que se funda o primeiro curso de Psicologia no Maranhão. 


\section{Universidade Federal no Maranhão [UFMA]}

O início da formação em Psicologia no contexto da Universidade Federal do Maranhão, em 1991, teve início no auge do movimento de revisão crítica da Psicologia Escolar no país. Nos primeiros anos da formação nessa IES, a ênfase do curso ainda privilegiava a formação clínica, especialmente devido ao perfil dos professores que compunham o quadro docente da instituição, reflexo do fortalecimento dos grupos com interesse na prática da Psicologia nos consultórios (Carvalho \& Marinho-Araujo, 2009; Galvão, 2016).

Embora o curso tenha sido fundado em 1991, o estágio específico para a Psicologia Escolar só foi iniciado em 1997, mesma época em que o curso de Psicologia da Universidade formava a sua primeira turma (Aires et al., 2011; Carvalho \& MarinhoAraujo, 2009). Por bastante tempo, observou-se que essa instituição não privilegiou a formação na área da Psicologia Escolar, característica não muito diferente das demais instituições do país (Marinho-Araujo, 2007). Apenas uma professora com experiência em Psicologia Escolar fazia parte do quadro docente da instituição entre o período de 1997 a 2006. Dessa forma, não havia a possibilidade de atender, de forma satisfatória, a demanda de estágio e nem as disciplinas relacionadas à área para uma formação adequada do psicólogo escolar. As disciplinas eram ministradas por professores que precisavam preencher sua carga horária, provocando, assim, uma lacuna na formação discente devido à falta de docentes com perfil específico para o ensino da Psicologia Escolar, uma vez que a disciplina não era de domínio teórico, metodológico e prático do professor responsável (Aires et al., 2011).

Em 2006, registrou-se um marco importante no contexto da UFMA. O Departamento de Psicologia da instituição aumentou para três o número de professores efetivos com experiência em Psicologia Escolar, por meio de concurso público. Esse momento inaugurou uma nova fase na formação discente: o contato com novas abordagens em Psicologia Escolar, o maior número de vagas oferecidas para o estágio na área, professores responsáveis pelas disciplinas afins com experiência em pesquisa e atuação em Psicologia Escolar entre outros aspectos (Aires et al., 2011; Galvão 2016).

Ainda naquele ano, o estágio em Psicologia Escolar começou a ser oferecido na abordagem comportamental e na abordagem históricocultural. Com base nessa última perspectiva da Psicologia, o estágio se configurou em duas modalidades de orientação e supervisão: uma voltada para uma Psicologia Escolar institucional, de caráter preventivo e relacional (MarinhoAraujo, 2014; Marinho-Araujo \& Almeida, 2005), conforme estabelecido no Projeto Político Pedagógico do Curso de Psicologia da UFMA (2014), e a outra voltada para avaliação e intervenção nas queixas escolares, conforme proposição teórico-metodológica de Neves (2009) (Aires et al., 2011; Carvalho, 2007; Conselho Regional de Psicologia, 2008; Galvão 2016). Essas perspectivas de atuação propõem a superação de uma atuação centrada no aluno, e envolve toda a instituição escolar em uma perspectiva dinâmica, sistêmica e processual de intervenção e mediação psicológica no contexto educativo. Reconhece-se que essas abordagens já refletiam o panorama de revisão crítica da Psicologia Escolar nacional e compuseram um escopo de propostas de formação significativas ao cenário do Maranhão.

Até 2013, as três professoras pertenciam ao quadro de docentes com perfil na área da Psicologia Escolar, até que houve um pedido de exoneração no referido ano por uma das docentes, o que deu abertura a vagas a novos professores na Universidade. Contudo, esta vaga foi direcionada, em 2014, para a área de Psicologia Organizacional e do Trabalho por decisão inicial de colegiado e deferimento da reitoria. Nesse mesmo ano, lançou-se o Edital No 268/2014 - PROEN para seleção de professor adjunto na referida área, não havendo aprovações (Galvão, 2016). 
No ano subsequente, as Diretrizes Curriculares para os Cursos de Psicologia foram aprovadas pelo parecer CNE/CES n 0062/2004, da Câmara de Educação Superior do Conselho Nacional de Educação, da qual houve a homologação pelo Ministro de Estado da Educação em abril de 2004 da Resolução n ${ }^{\circ}$ 08, de 07 de maio de 2004 , instituindo as DCNs para todos os cursos que ofertavam a graduação nesta área. Nesse mesmo ano, o Projeto Político Pedagógico do Curso de Psicologia da UFMA é reeditado, passando a ofertar uma matriz curricular que comporta disciplinas obrigatórias, disciplinas optativas, atividades de estágios e monografia, em uma carga horária total de 4.085 horas (3.885 horas de atividades regulares e 200 horas de atividades complementares). São duas ênfases admitidas pelo curso de Psicologia e estão em consonância com as Diretrizes Curriculares de Graduação em Psicologia (Resolução, 2001): (1) processos clínicos e saúde e (2) processos psicossociais, em conformidade às ênfases estabelecidas pelas DCNs. Tais ênfases detêm caráter facultativo, em consonância ao estabelecido na Resolução $\mathrm{n}^{\circ}$ 08/2014 “ $§ 3^{\circ}$ A instituição deverá oferecer, pelo menos, duas ênfases curriculares que assegurem possibilidade de escolha por parte do aluno" (Ministério da Educação, 2004). Na segunda ênfase, processos psicossociais, estão alocadas a disciplina Psicologia Educacional e Escolar (60h) e o Estágio Básico em Psicologia Escolar (45h) desta instituição.

Com PPC do curso de Psicologia reestruturado, no ano seguinte, em 2015, um novo edital élançado para a mesma vaga de professor adjunto para a área de Psicologia Organizacional e do Trabalho; dois professores foram classificados, um deles permaneceu na área da Psicologia Organizacional e do Trabalho, e o outro docente aprovado foi remanejado para a área de Psicologia Escolar e Educacional por ter perfil para a formação nesta área (Galvão, 2016). Até a presente data, registram-se ainda três docentes do curso de Psicologia da UFMA, que respondem pela área de ensino de disciplinas, pesquisa e estágio em Psicologia Escolar e Educacional; duas com doutoramento completo, e uma com doutoramento em andamento (Conselho Regional de Psicologia, 2015b; Galvão, 2015).

Cabe ainda destacar que a Universidade Federal do Maranhão é a única IES regional que possui um programa de pós-graduação strictu senso em Psicologia em nível de mestrado acadêmico. Implementado pela Resolução $n^{\circ}$ 763-CONSEPE, de 25 de maio de 2010, o mestrado concentra uma área, a Psicologia, e duas linhas de pesquisa, a Linha 1: Processos Clínicos e Saúde, e a Linha 2: Processos Psicossociais (Universidade Federal do Maranhão, 2010). Mais recentemente, em 2016, o departamento de Psicologia da UFMA, por meio deste Programa, lançou o Edital PPPGI $n^{\circ}$ 039/2016, que já inclui ênfases que contemplam, pela primeira vez na história do Maranhão, o tema de investigação em Psicologia da Educação e Psicologia Educacional e Escolar, a ser ofertado pela linha de pesquisa intitulada História, Epistemologia e Fenômenos Psicológicos, o que demonstra avanços no campo da Psicologia na Educação do estado no âmbito da Universidade Federal.

\section{Universidade CEUMA}

O curso de Psicologia da Universidade CEUMA consolidou-se em 1998 (na ocasião, ainda Centro Universitário), e foi o segundo a ser ofertado no estado maranhense. Em seu princípio, havia dois docentes que respondiam por áreas relacionadas à Psicologia Escolar e Educacional. Nos anos 2000, esse quadro é ampliado para quatro docentes que tanto ministravam disciplinas, como a
Psicologia do Desenvolvimento e Psicologia da Aprendizagem, quanto supervisionavam estágios da área de Psicologia Escolar (Galvão, 2016).

$\mathrm{Na}$ matriz curricular, já orientada pelas Diretrizes Curriculares Nacionais dos anos 2004, constatava-se o estágio em Psicologia Escolar em duas modalidades. Primeiro, o estudante deveria obrigatoriamente realizar estágio observacional 
nos dois períodos do penúltimo ano do curso de Psicologia com carga horária de 60h (duas áreas por semestre, totalizando $240 \mathrm{~h}$ por ano), e necessariamente passava pelas áreas de Psicologia Escolar, Psicologia Organizacional, Psicologia Clínica e Psicologia Hospitalar. Já a segunda modalidade de estágio, também obrigatório, referia-se ao estágio curricular profissionalizante no último ano do curso, com carga horária de $120 \mathrm{~h}$. O estudante de Psicologia, nesta ocasião, deveria optar por uma das áreas, como Psicologia Escolar, Psicologia Jurídica, Psicologia Clínica, entre outras. Nota-se que a oportunidade de imersão de estágio obrigatório, ainda que classificado para fins de observação das práticas em Psicologia Escolar, era uma excelente oportunidade para o psicólogo em formação no Maranhão ter contatos iniciais com a realidade educacional do estado.

Importante ainda destacar que parte do quadro docente desta instituição, em seu princípio, eram professores adjuntos e substitutos da Universidade Federal do Maranhão, dada a modesta inserção de psicólogos voltados para o exercício da docência com a titulação de mestres (Aires et al., 2011; Galvão, 2016). Muitos dos professores desta universidade migraram de outras unidades federativas, como a Universidade Federal do Pará, Universidade Federal da Paraíba, Universidade Estadual do Rio de Janeiro e Universidade de Brasília (Araujo, 2005a, 2005b). Na área da Psicologia Escolar, notava-se uma característica semelhante ao que ocorria no âmbito da Universidade Federal do Maranhão: as disciplinas eram ministradas por professores que precisavam preencher sua carga horária e cujo perfil de formador específico não era condizente com esse campo de atuação (Carvalho, 2007; Carvalho \& Marinho-Araujo, 2009; Galvão, 2016).

Entre os anos 2002 e 2007, quatro professores respondiam pela Psicologia Escolar na Universidade Ceuma. Ainda neste último ano, a instituição deixou de contar com um docente devido a pedido de desligamento da instituição para assumir novos trabalhos. Anos mais tarde, a partir de 2013, três profissionais da Psicologia com formação em nível de pós-graduação stricto sensu na área da Educação foram incorporados ao quadro de docentes da instituição.

Importante destacar que, desde 2013, a referida instituição passou a ter a configuração de universidade, e a ênfase na pesquisa científica torna-se uma meta político-institucional para os docentes. Em 2014, paralelamente à renovação do PPC do curso de Psicologia da UFMA, a Universidade Ceuma reestruturou o seu Projeto Político Pedagógico do Curso de Psicologia. A matriz curricular comporta disciplinas de conteúdos teórico-práticos (3.040 horas), estágio supervisionado (760 horas), atividades complementares (200 horas), totalizando uma carga horária de 4.000 horas. O PPC do curso foi estruturado para o desenvolvimento do perfil de egresso em torno de eixos estruturantes consoantes aos estabelecidos pelas Diretrizes Curriculares Nacionais, entre os quais se destaca o eixo "ix. Processos de avaliação e intervenção escolar-educacional" (Universidade Ceuma, p. 36, 2014).

As ênfases do curso também são aspectos importantes para caracterizar a qualidade impressa no projeto de curso, considerando também os aspectos regionais para os quais o psicólogo precisa estar preparado (Marinho-Araujo, 2007). O PPC do curso de Psicologia da Universidade Ceuma elege três ênfases curriculares orientadas pelas Diretrizes Curriculares para os cursos de Psicologia, em torno das quais são articulados disciplinas, estágios e atividades complementares. São elas: (1) Psicologia, Processos de Intervenção Psicossociais Institucionais e Organizacionais; (2) Psicologia e Processos de Prevenção e Promoção da Saúde e Gestão; e (3) Psicologia, Processos Clínicos e Avaliação Diagnóstica. No Projeto do Curso, explicita-se que "essa decisão (de escolha das ênfases do curso) sustenta-se no fato de que no Maranhão a Psicologia como ciência e profissão se caracteriza como um campo aberto a ser construído. As ênfases escolhidas apresentam afinidades entre si e, especialmente, atendem à demanda atual (de trabalho) da região" (Universidade Ceuma, p. $36,2014)$. Desde a implementação do PPC até a atualidade, são ofertados a disciplina de Psicologia 
Escolar e Dificuldades de Aprendizagem, com carga horária de 60 horas, e o estágio em Psicologia Escolar no Estágio Supervisionado Específico em Processos de Intervenções Psicossociais, Institucionais e Organizacionais, com carga horária de 240 horas, ambas atreladas à ênfase 1 do PPC curso (Universidade Ceuma, 2014).

Em 2015, mais um docente com doutorado na área específica em Psicologia Escolar e Educacional foi contratado, totalizando até o presente momento cinco profissionais que respondem pela área na Universidade Ceuma (Galvão, 2016). Neste mesmo ano, fundou-se, por iniciativa de professores de Psicologia, o Núcleo de Estudos em Psicologia na Educação do Maranhão - NEPEMA (Universidade Ceuma, 2015). Este núcleo integra professores da Universidade Ceuma e de outras duas instituições formadoras em Psicologia Escolar e Educacional no estado, UFMA e Faculdade Pitágoras, por meio de acordo técnico-científico entre as IES. A parceria interinstitucional visa fortalecer a formação de pesquisadores estudantes de Psicologia para o campo da Educação, especialmente no contexto da atuação nas instituições escolares, e mediar o desenvolvimento de competências profissionais próprias ao trabalho do psicólogo que atua na interface com a Educação.

Derivado deste núcleo, foi fundado, em 2016, o Grupo de Pesquisa Psicologia, Educação e Educação Especial: Processos de Desenvolvimento e Intervenção, devidamente cadastrado no Diretório do Grupo de Pesquisa do Conselho Nacional de Desenvolvimento Científico e Tecnológico (CNPq). Este Grupo integra pesquisas em quatro grandes linhas: (1) Mapeamento da Psicologia Escolar e Educacional no Maranhão: História, Campos de Atuação e Tendências; (2) Avaliação e Desenvolvimento de Competências no Ensino Superior; (3) Avaliação e Desenvolvimento de Metodologias de Intervenção Psicológica em Transtornos Globais do Desenvolvimento e Inclusão Escolar; e (4) Psicologia Escolar, Desenvolvimento Humano e Processos Educativos. O grupo visa incrementar a produção de conhecimento em Psicologia no estado, privilegiando atividades de ensino, pesquisa e extensão universitária, desenvolvendo estudos em parcerias regionais e nacionais, e participando da elaboração de políticas públicas regionais. As ações do NEPEMA também contam com a cooperação acadêmica externa, como a UnB (Universidade de Brasília, Brasília-DF).

O cenário da formação em Psicologia Escolar e Educacional da Universidade Ceuma desponta para o incremento da qualidade da formação do psicólogo escolar maranhense, haja vista o vasto campo da Educação para o qual o profissional pode comprometer-se, politicamente e forma ética, com a missão educacional de que se revestem inúmeras instituições desta região (Conselho Regional de Psicologia, 2008, 2015a, 2015b, 2016).

\section{Considerações Finais}

Nos últimos anos, as disciplinas, pesquisas, estágios e projetos de extensão em Psicologia Escolar da UFMA e Universidade Ceuma têm contemplado outras propostas e modelos de trabalho, tais como a atuação do psicólogo escolar na implementação das políticas públicas e institucionais (Dazzani, 2010; Guzzo et al., 2010; Fleith, 2011; Mitjáns-Martínez, 2007, 2009; Marinho-Araujo, Neves, Penna-Moreira, \& Barbosa, 2011), na formação de professores (Marinho-Araujo \& Almeida, 2005; Soares, 2008); nas instituições de ensino superior (MarinhoAraujo, 2009, 2014), nas organizações não governamentais (Dadico, 2003; Dias, 2007; Soares, 2008; Soares \& Marinho-Araujo, 2010), todas ancoradas por perspectivas teórico-metodológicas e ideológicas menos deterministas e com ênfase em processos históricos e sociais.

Cabe ainda enfatizar acerca da diversidade dos campos para os quais os estagiários em Psicologia Escolar são orientados, o que lhes permite ampliar a experiência na área na atualidade. Além da 
escola, tem-se orientado estágio em instituições de acolhimento para crianças em situação de risco e vulnerabilidade social, instituições de cumprimento de medidas socioeducativas, organizações não governamentais, crechesescola, educação superior, entre outros espaços de compromisso com a educação formal e não formal.

A ênfase curricular atual do curso de formação em Psicologia da UFMA e da Universidade CEUMA, consoante com as Diretrizes Curriculares Nacionais para os cursos de graduação em Psicologia (Resolução n ${ }^{\circ}$ 5, de 15 de março 2011), está voltada para a formação de competências visando o perfil de egresso generalista. De acordo com Marinho-Araujo (2007), as diretrizes são consideradas "um avanço em relação ao Currículo Mínimo em vigor até então, pois orientam a construção de um perfil profissional competente e comprometido historicamente com as demandas sociais na formação inicial do psicólogo" (p. 18). Isso é importante para garantir as possibilidades de transversalização dos saberes com a realidade regional.

Entretanto, a autora sinaliza para o cuidado sobre os meios operacionais pelos quais se almeja concretizar a formação deste perfil, alegando que a constituição das competências para lidar com as demandas sociopolíticas não se dará apenas pelas reformulações legais ou institucionais firmadas pelo sistema educacional superior. É necessário, pois, promover a inserção dos psicólogos escolares em formação nos contextos reais de atuação e incitar processos de reflexão teórica e metodológica que orientem a conscientização dos seus papéis e das funções no que compete a especificidade do conhecimento psicológico nos espaços de intervenção.

Orientado por essas mudanças, o perfil do psicólogo escolar tem mobilizado novas discussões no âmbito da formação promovida pelas IES maranhenses na última década, gerando propostas de restruturações curriculares em torno da formação inicial e conduzindo a novos rumos institucionais. Como desdobramento dessas mudanças, tem-se assistido a um aumento significativo de trabalhos de conclusão de curso voltados para o mapeamento da realidade socioeducacional maranhense, visando explorar as possibilidades de intervenção do psicólogo escolar nos contextos educacionais (Ribeiro \& Galvão, no prelo).

Apesar desses avanços iniciais, ainda se faz necessário criar outras possibilidades de formação, inicial e continuada, na área da Psicologia Escolar, tais como cursos de pós-graduação latu sensu e stricto sensu, projetos de pesquisa e extensão, estratégias políticas para incentivar interlocução com outras instituições de ensino em Psicologia do estado, bem como para estreitar debates entre profissionais e pesquisadores do Maranhão e de outros estados brasileiros, políticas públicas de ampliação dos espaços de atuação do psicólogo escolar, entre outros desafios profissionais que se comprometam eticamente com a realidade social do estado do Maranhão (Aires et al., 2011; Carvalho, 2007; Carvalho \& Marinho-Araujo, 2009; Soares, 2008).

Os próximos desafios que se colocam no cenário da Psicologia Escolar e Educacional no Maranhão devem formar várias frentes, entre as quais destacam-se (1) discussão e definição do perfil profissional do psicólogo escolar para a Rede Estadual de Ensino do Maranhão, a ser esclarecido em edital para concurso público; (2) elaboração de mapa de competências, consoantes ao perfil profissional esperado, para o planejamento de capacitação dos psicólogos escolares recémcontratados; (3) articulação entre Secretaria de Educação Estadual e Municipal e Instituições de Ensino Superior dos cursos de Psicologia para elaboração de projetos de extensão e outros projetos de parcerias que favoreçam a formação em Psicologia Escolar e Educacional; (4) elaboração de políticas públicas que prevejam a participação do psicólogo escolar e educacional, assim como outros profissionais, no cenário do debate sobre a Educação do estado; (5) fortalecimento da formação inicial e continuada por meio das instituições de ensino superior em Psicologia, com ênfase na capacitação por competências (de acordo com as Diretrizes Curriculares Nacionais para os cursos de graduação em Psicologia, CNE/CES n ${ }^{\circ}$ 
5, de 15 de março 2011), de forma a garantir a constituição de uma identidade profissional segura e comprometida com a qualidade da educação no Maranhão; (6) consolidação de políticas públicas de formação continuada em serviço para os psicólogos escolares; (7) divulgação do trabalho da Psicologia Escolar e Educacional junto à população maranhense.

Observa-se que, atualmente, têm surgido relevantes iniciativas que demonstram que o psicólogo escolar tem buscado atuar em consonância ao que Mitjáns-Martínez (2009) define como formas emergentes de atuação, desenvolvendo ações cada vez mais abrangentes, com o propósito de contribuir para a otimização do processo educativo. As contribuições teóricometodológicas devem ser suscitadas entre os psicólogos escolares maranhenses em prol da transformação da realidade do estado, por meio do incentivo à otimização do ensino, pesquisa $\mathrm{e}$ extensão universitária. Faz-se necessário que os estudos da Psicologia Escolar e Educacional no Maranhão estejam cada vez mais comprometidos com a mudança de um panorama social repleto de injustiças que segregam e excluem a população menos favorecida economicamente.

\section{Referências}

Aires, J., Soares, P. G.,\& Carvalho, T. O. (2011). Psicologia Escolar no Maranhão: História, Formação e Atuação. Mesaredonda apresentada no VII Congresso Brasileiro de Psicologia do Desenvolvimento da Sociedade Brasileira de Psicologia do Desenvolvimento, Brasília-DF.

Antunes, M. A. M. (2003). Psicologia e Educação no Brasil: Um olhar histórico-crítico. In M. E. M. Meira, \& M. A. M. Antunes (Eds.), Psicologia escolar: Teorias críticas (pp. 139-168). São Paulo: Casa do Psicólogo.

Antunes, M. A. M. (2008). Psicologia Escolar e Educacional: História, compromisso e perspectivas. Revista Psicologia Escolar e Educacional 12(2), 469-475. doi: 10.1590/ S1413-85572008000200020

Antunes, M. A. M. (2011). Psicologia e Educação no Brasil: Uma análise histórica. In R. G. Azzi, \& M. H. T. Gianfaldoni (Eds.), Psicologia e Educação (pp. 9-32). São Paulo: Casa do Psicólogo.

Araújo, M. A. P. (2005a). A Psicologia no Maranhão: Percursos Históricos. São Luís: EDUFMA.

Araújo, M. A. P. (2005b). Conhecendo a Psicologia no Maranhão. Estudos e Pesquisas em Psicologia, 5(1), 144157.

Barbosa, D. R. (2012). Contribuições para a construção da historiografia da Psicologia Educacional e Escolar no Brasil. Psicologia: Ciência e Profissão, 32(número especial), 104-123.

Barbosa, D. R.,\& Souza, M. P. R. (2012). Psicologia Educacional ou Escolar? Eis a questão. Revista Psicologia Escolar e Educacional 16(1), 163-173. doi: 10.1590/ S1413-85572012000100018

Bock, A. M. B. (1999). A Psicologia a caminho do novo século: Identidade profissional e compromisso social. Estudos de Psicologia, 4(2), 315-329.

Carvalho, T. O. (2007). Atuação em psicologia escolar: o desenvolvimento de competências para a mediação da escolha profissional em São Luís-MA (Dissertação de Mestrado). Universidade de Brasília, Brasília.

Carvalho, T. O., \& Marinho-Araujo, C. M. (2009). Psicologia escolar no Brasil e no Maranhão: percursos históricos e tendências atuais. Revista Psicologia escolar e Educacional, 13(1), 65-73. doi: 10.1590/S1413-85572009000100008

Collares, C. A. L.,\& Moysés, M. A. A. (1992). A história não contada dos distúrbios de aprendizagem. Cadernos Cedes, 46(28), 31-48.

Collares, C. A. L.,\& Moysés, M. A. A. (1996). Preconceitos no Cotidiano Escolar: Ensino e medicalização. São Paulo: Cortez.

Conselho Regional de Psicologia do Maranhão. (2008). Relatório da Fundação da Comissão de Psicologia Escolar e Educacional do CRP-MA. São Luís: Comissão de Psicologia na Educação do Maranhão/CRP-MA. Recuperado de http://crpma.org.br/pagina/psicologia-na-educacao

Conselho Regional de Psicologia do Maranhão (2015a). Relatório de Participação do Psinaed - MA no Seminário Nacional Comissão de Psicologia na Educação do Maranhão do Conselho Federal de Psicologia. Comissão de Psicologia na Educação do Maranhão, São Luís-MA. Recuperado de http://crpma.org.br/pagina/psicologia-na-educacao Conselho Regional de Psicologia do Maranhão (2015b). Relatório da Reativação da Comissão de Psicologia na Educação do Maranhão - PSINAED. Comissão de Psicologia na Educação do Maranhão, São Luís-MA. Recuperado de http://crpma.org.br/pagina/psicologia-na-educacao Conselho Regional de Psicologia do Maranhão (2016). Relatório de Participação do Psinaed - MA no Seminário Nacional Comissão de Psicologia na Educação do Maranhão do Conselho Federal de Psicologia. Comissão de Psicologia na Educação do Maranhão, São Luís-MA. Recuperado de http://crpma.org.br/pagina/psicologia-na-educacao 
Correia, M., \& Campos, H. R. (2004). Psicologia Escolar: Histórias, tendências e possibilidades. In O. $\mathrm{H}$. Yamamoto, \& A. C. Neto, (Eds.), O psicólogo e a escola: Uma introdução ao estudo da psicologia escolar. (pp. 137185). Natal: EDUFRN.

Cunha, E. O. C., \& Dazzani, M. V. M. (2016). Da repulsa da escola à diferença: Historicizando raízes, perspectivando saídas. In M. V. Dazzani, \& V. L. T. Souza (Eds), Psicologia Escolar Crítica: Teoria e Prática nos Contextos Educacionais (pp. 57-76). Campinas: Alínea.

Dadico, L. (2003). Atuação do psicólogo em organizações não governamentais na área da educação (Dissertação de Mestrado). Universidade de São Paulo: São Paulo.

Dazzani, M. V. M. (2010). A Psicologia Escolar e a educação inclusiva: Uma leitura crítica. Psicologia, Ciência e Profissão, 30(2), 362-375. doi: 10.1590/S141498932010000200011

Dias, C. S. (2007). Educação não formal e emancipação humana sob o olhar da Psicologia (Dissertação de Mestrado). Pontifícia Universidade Católica de Campinas: Campinas.

Dias Sobrinho, J. (2013). Educação superior, bem público, equidade e democratização. Avaliação: Revista da Avaliação da Educação Superior, 18(1), 107-126. doi: 10.1590/S1414-40772013000100007

Fleith, D. S. (2011). A Política Nacional de Educação Especial na Perspectiva da Educação Inclusiva: Desafios para o Psicólogo Escolar. In C. M. Marinho-Araujo, \& R. S. L. Guzzo (Eds.), Psicologia Escolar: Identificando e superando barreiras (pp. 33-46). Campinas: Alínea.

Galvão, P. (2016). Psicologia Escolar no Maranhão: Uma História de Lutas e Conquistas. Palestra Apresentada do III Encontro de Psicólogos no Instituto Federal do Maranhão, São Luís-MA.

Galvão, P., Andrade, L. M. G.,Beckman, M., Melo, E. R. M. S. F., Ribeiro, W. R., Silva, E. P., Santos, E. O., \& Lobo, E. A. (2016). Psicologia Escolar em ONGs no Maranhão: Análise de um Cenário em Potencial para Atuação. Mesa Redonda apresentada no IV Congresso de Saúde e Bem-Estar da Universidade Ceuma, São Luís-MA.

Guzzo, R. S. L. (2005). Escola amordaçada: Compromisso do psicólogo com este contexto. In A. M. Martinez (Org.), Psicologia Escolar e compromisso social: Novos discursos, novas práticas (pp. 17-29). São Paulo: Alínea.

Guzzo, R. S. L. (2008). Psicologia em instituições escolares e educativas. In Conselho Federal de Psicologia. Ano da Psicologia na Educação Textos Geradores. Brasília: CFP.

Guzzo, R. L. S. (2011). Desafios cotidianos em contextos educativos: A difícil formação de psicólogos para a realidade brasileira. In R. G. Azzi, \& M. H. T. A. Giandolfi (Orgs.), Psicologia e Educação (pp. 253-270). São Paulo: Casa do Psicólogo.

Guzzo, R. S, Costa, A. S., \& Sant'Anna, I. M. (2009). Formando psicólogos escolares: Problemas, vulnerabilidades, desafios e horizontes. In C. M. Marinho-Araújo (Eds.), Psicologia Escolar: Novos cenários e contextos de pesquisa, prática e formação (pp. 35-52). Campinas: Alínea.
Guzzo, R. S., Mezzalira, A. S. C, Moreira, A. P. G., Tizzei, R. P., \& Neto, W. M. F. S. (2010). Psicologia e Educação no Brasil: Uma visão da história e possibilidades nessa relação. Psicologia: Teoria e Pesquisa, 26(número especial), 131-141. doi: 10.1590/S0102-37722010000500012

Maluf, M. R., \& Cruces, A. V. V. (2008). Psicologia educacional na contemporaneidade. Boletim Academia Paulista de Psicologia, 1(8), 71-99.

Marinho-Araujo, C. M. (2007). A Psicologia Escolar nas diretrizes curriculares: Espaços criados, desafios instalados. In H. R. Campos (Org.), Formação em Psicologia Escolar: Realidades e perspectivas (pp. 17-48). Campinas: Alínea.

Marinho-Araujo, C. M. (2009). Psicologia Escolar na educação superior: Novos cenários de intervenção e pesquisa. In C. M. Marinho-Araújo (Org.), Psicologia Escolar: Novos cenários e contextos de pesquisa, formação e prática (pp. 155-202). Campinas: Editora Alínea.

Marinho-Araujo, C. M. (2010). Psicologia Escolar: Pesquisa e intervenção. Em Aberto, 23(83), 17-35.

Marinho-Araujo, C. M. (2014). Intervenção institucional: Ampliação crítica e política da atuação em Psicologia Escolar. In R. S. L. Guzzo (Org.), Psicologia escolar: Desafios e bastidores na educação pública (pp. 153-176). Campinas: Alínea.

Marinho-Araujo, C. M. (2016). Perspectiva histórico-cultural do desenvolvimento humano: Fundamentos para atuação em Psicologia Escolar. In M. V. Dazzani, \& V. L. T. Souza (Eds.), Psicologia Escolar Crítica: Teoria e Prática nos Contextos Educacionais (pp. 37-56). Campinas: Alínea.

Marinho-Araujo, C. M., \& Almeida, S. F. C. (2005). Psicologia Escolar: Construção e consolidação da identidade profissional. Campinas: Alínea.

Marinho-Araujo, C. M. M., Neves, M. B. J., Penna-Moreira, P. C. B., \& Barbosa, R. M. (2011). Psicologia Escolar no Distrito Federal: História e compromisso com políticas públicas. In R. L. S. Guzzo, \& C. M. Marinho-Araujo (Eds.), Psicologia Escolar: Identificando e superando barreiras (pp. 47-76). Campinas: Alínea

Massimi, M. (1990). História da Psicologia brasileira: Da época colonial até 1934. São Paulo: EPU.

Massimi, M., \& Guedes, M, C. (2004). História da Psicologia no Brasil: Novos estudos. São Paulo: Educ.

Meira, M. E. M. (2000). Psicologia Escolar: Pensamento crítico e práticas profissionais. In E. T. Tanamachi, M. Proença, \& M. L. Rocha (Orgs.), Psicologia e Educação: Desafios teórico-práticos (pp.36-52). São Paulo: Casa do Psicólogo.

Meira, M. E. M. (2012). Para uma crítica da medicalização na educação. Psicologia Escolar e Educacional, 16 (1), 135-142. doi: 10.1590/S1413-85572012000100014

Mitjáns-Martínez, A. (2007). O psicólogo escolar e os processos de implantação de políticas públicas: Atuação e formação. In H. R. Campos (Org.), Formação em Psicologia Escolar: Realidades e perspectivas (pp. 47-59). Campinas: Alínea. 
Mitjáns-Martínez, A. M. (2009). Psicologia Escolar e Educacional: Compromissos com a educação brasileira. Psicologia Escolar e Educacional, 13(1), 169-177.

Neto, W. M. F. S., Guzzo, R. S. L., \& Moreira, A. P. G. (2014). In R. S. L. Guzzo (Org.), Psicologia Escolar: Desafios e bastidores na educação pública (pp. 197-216). Campinas: Alínea.

Neves, M. M. B. J. (2007). Formação inicial em Psicologia Escolar: Questões apontadas por alunos de graduação. In H. R. Campos (Org.), Formação em Psicologia Escolar: Realidades e perspectivas (pp. 49-68). Campinas: Alínea.

Neves, M. M. B. J. (2009). Atuação dos psicólogos escolares no Distrito Federal. In C. M. Marinho-Araujo (Ed.), Psicologia Escolar: Novos cenários e contextos de pesquisa, formação e prática (pp. 55-74). Campinas: Editora Alínea.

Oliveira, C. B. E. \& Marinho-Araujo, C. M. (2009). Psicologia Escolar: Cenários atuais. Estudos e Pesquisas em Psicologia, 9(3), 648-663.

Patto, M. H. S. (1999). A produção do fracasso escolar: Histórias de submissão e rebeldia. São Paulo: Casa do Psicólogo.

Patto, M. H. S. (2005). Exercícios de indignação: Escritos de educação e psicologia. São Paulo: Casa do Psicólogo.

Patto, M. H. S. (2008). Ciência e política na Primeira República: Origens da Psicologia Escolar. In A. M. JacóVilela, \& F. Jabur, H. B. C. Rodrigues (Eds.), Clio-Psyché: Histórias da Psicologia no Brasil (pp. 187-206). Rio de Janeiro: Biblioteca Virtual de Ciências Humanas do Centro Edelstein de Pesquisas Sociais.

Polidori, M. M., Marinho-Araújo, C. M., \& Barreyro, G. B. (2006). SINAES: Perspectivas e desafios na avaliação da Educação Superior brasileira. Ensaio, 14(53), 425-436.

Rabelo, M. L. (2013). Avaliação educacional: fundamentos, metodologias e aplicações no contexto brasileiro. Brasília: SBM.

Ribeiro, V. M. (2006). A implantação do ensino secundário público maranhense: Liceu Maranhense. (Dissertação de Mestrado), Departamento de Educação, Universidade Federal do Maranhão: São Luís.

Ribeiro, C. G. (2015). A contribuição dos cursos de Psicologia na Formação de Psicólogos Escolares no Maranhão: Uma análise documental. (Trabalho de Conclusão de Curso não publicado), Departamento de Psicologia, Universidade CEUMA: São Luís.

Ribeiro, C. G., \& Galvão, P. (no prelo). A Formação na Área da Psicologia Escolar em Instituições de Ensino Superior do Maranhão: Uma Análise Documental. In P. Galvão, R. E. Figueiredo, \& D. C. Matos (Eds), A Psicologia no Campo da Educação no Maranhão: História, Atuação e Tendências Atuais. EDUFMA: São Luís.

Soares, P. G., (2008). Psicologia Escolar e o desenvolvimento adulto: Um estudo sobre o perfil de educadoras sociais em uma ONG de São Luís/MA (Dissertação de Mestrado), Instituto de Psicologia, Universidade de Brasília: Brasília. Soares, P. G. \& Marinho-Araujo, C. M. M. (2010). Psicologia Escolar em contextos de Educação Social: Práticas emergentes. Revista Psicologia Escolar e Educacional, 14(1), 45-54. doi: 10.1590/S1413-85572010000100005

Tanamachi, E. R., (2000). Mediações teórico-práticas de uma visão crítica em Psicologia Escolar. In E. de R. Tanamachi, M. Proença, \& M. Rocha (Orgs.), Psicologia e Educação: Desafios teórico-práticos (pp. 73-102). São Paulo: Casa do Psicólogo.

Tanamachi, E. R., \& Meira, M. E. M. (2003). A atuação do psicólogo como expressão do pensamento crítico em Psicologia e Educação. In M. E. M. Meira, \& M. A. M. Antunes (Eds.), Psicologia Escolar: Práticas críticas (pp.1727). São Paulo: Casa do Psicólogo.

Universidade Ceuma (2014). Projeto Político Pedagógico do Curso de Graduação em Psicologia da Universidade Ceuma. São Luís: Universidade Ceuma.

Universidade Ceuma (2015). Projeto de Fundação do Núcleo de Estudos de Psicologia na Educação do Maranhão NEPEMA do Curso de Psicologia. Universidade Ceuma, São Luís-MA.

Universidade Federal do Maranhão (2010). Regimento Interno do Programa de Pós-Graduação Stricto Sensu em Psicologia. São Luís: UFMA.

Universidade Federal do Maranhão (2014). Projeto Político Pedagógico do Curso de Graduação em Psicologia da Universidade Federal do Maranhão. São Luís: UFMA. 